\title{
Automation of Process Performance Management in a Company
}

\author{
Nemanja TASIĆ, Željko ĐURIĆ, Dane MALEŠEVIĆ, Rado MAKSIMOVIĆ, Nikola RADAKOVIĆ
}

\begin{abstract}
The paper describes the automation of process performance management in a particular company, using specially developed client application. Performance management process is based on an analysis of data from the process. The main problem, of analysis in real cases, is the low availability of data from the process and the impossibility of obtaining the analysis results in real time. A detailed specification of business requirements related to performance management in the organization is presented as well as the way of application of WCF (Windows Communication Foundation) services, the concept of business intelligence, methodology for data warehousing DW (Data Warehousing), and application of Silverlight technology for solving this problem. In particular, it shows the implementation of Silverlight client application for processes performance management within the company.
\end{abstract}

Keywords: company; control; key performance indicators; process quality

\section{INTRODUCTION}

The main bases of successful business of a company are comprised of the following elements:

a) clearly determined basic organizational matters - the vision, mission, goals, policies and plans,

b) defined set of processes goals that are related to: needs of customers, survival and development of company, the shareholders' interest, employees satisfaction and social responsibility of company in the surrounding,

c) adequate human and infrastructural resources for the processes realization,

d) defined way of the processes realization, including the sequence of activities, responsibilities of employees and documents containing the necessary data and

e) an established management system that is based on the feedback that involves the analysis of data from the processes - processes performance measurement as a basis for making management decisions.

The focus of this work is a detailed analysis of the last of the above elements (marked "e").

According to the requirements of ISO 9001:2015 standard (International Organization for Standardization, 2015 [19]) the company must apply suitable methods for monitoring and processes performance measurement. These methods must demonstrate the ability of processes to achieve planned results. All processes in the company are subject to measurement and monitoring. General supervision of the processes performance is achieved through periodic control of business plan realization that specifies core activities and objectives for all processes. Methods of measurement and control of processes characteristics during the course of their implementation shall be regulated by appropriate procedures. Monitorig of the characteristics of the overall company business is conducted in the work processes of the management of company. Monitoring includes periodical control of the realization of operations plan which specifies the basic technical and economic outcomes and goals for annual period, as well as specific analysis of the characteristics the performance of all processes.
Processes performance analysis is carried out to provide information about the achieved level of quality of the process in a systemic approach, and as the basis for management by objectives and improvements.

In the process of analysis, the quality of data and information from the processes is essential, as well as their timeliness and availability, to all participants in the analysis - the processe's managers and the company's top management. In that sense, there is also expressed need that the information system of the company, in addition to the key role related to business process automation, should be expanded in such a way to include elements that provide such analysis. This paper provides a practical approach to this expansion of IT support to company business.

\section{LITEATURE REVIEW}

Control of achievement of strategic goals is done by measuring and comparing them with data on business results from a company database, establishing a process measurement program in the company (List et al. 2005 [1]).

Previous research (from [2] to [11]) related to performance measurement models is primarily based on partial, individual performance measurement models, whose concept did not give insight into the basic factors of the business results achieved, and no insight into aspects of the business to improve and in the future affect the key performance of the company.

In the early 1990's a new organization performance measuring system was developed under the name Balanced Scorecard (BSC). This was just a reporting tool in the beginning, but included the critical aspects of business. Today, BSC is a system, or a methodology that transforms the mission, vision and strategy of the organization into a comprehensive cluster of selected measures that secure a framework for strategy implementation. It is used for the transformation of organizational strategic goals to performance indicators.

For the company to accumulate the knowledge necessary to achieve its goals, measurement of Key Performance Indicators (KPIs) is obligatory. Measuring and reporting in the Balance Scorecard concept are done through Key Performance Indicators in light of certain perspectives that include different key processes in 
business. These are, originally (Kaplan and Norton, 1999 [2]) financial perspective, buyers perspective, internal processes perspective and learning and development perspective. Due to different views on the measuring problem and success rating additional different measuring methods were developed such as the Balanced Scorecard (BSC), System of 20 keys, Six-Sigma models, TQM, etc. Lately, the Balanced Scorecard has become the most used model due to its rationality and reliability. It tracks an optimal number of key characteristics, whose selection comes from the vision and strategy of the company. The research (Kaplan and Norton, 2001 [3]) has shown that the BSC, in comparison to other models, is mostly directed to the results and nearest to the consumer. It is easily connected to other tools for success measuring that are used in the company.

Various researchers are trying to determine a set of quantitative measures which would be used for advanced control of software product development processes, which includes the initiation and control of implementation of improvement programs. Wang et al. 2006 [4] proposed a set of measures developed on a case study from industry. Abran et al. 2004 [5] give an example of modern methods for measuring the performance of the company with a proposal for the effective processes management to achieve business excellence. Management based on quantitative data is one of the conditions of a higher level of maturity in the organization and the management model based on the International Standards Organization, stresses the importance of quantitative measurement and management processes. A piece of evidence for the importance of quantitative measurements, for example, in developing software programs is the fact that Software Engineering Body of Knowledge, SWEBOK (as one of the standard references for software engineering), plans to introduce a special area of knowledge dedicated only to measurements. New starting point in developing models for measuring key performance indicators of the company is a concept given by Kaplan and Norton, 2011 [6], which stems from the vision and strategy of the company, and which is essentially a balanced model of corporate governance, target performance and their criteria, based on financial and nonfinancial "perspectives". Model for measuring key performance indicators in a particular company (Djuric et al. 2010 [7], Djuric et al. 2013 [18]) was developed as a part of a quality management system. Garengo, 2009 [8] contributes to the understanding of performance measurement systems (PMSs) in small and medium companies (SMEs). The paper proposes a framework for the classification of PMSs and shows how it can be used to study the PMSs, and it is adopted by a group of leading Italian SMEs. Skibniewski et al. 2009 [9] deal with key issues in the enterprise resource planning (ERP), and systemic application used in the construction industry. Gongbo et al. 2011 [10] and Radujković et al. 2010 [11] identified KPIs to measure performance management in construction industry.

\section{THE ANALYSIS OF PROCESS PERFORMANCE 3.1 Procedure to Analyze Process Performance}

Process performance is a set of data which in accordance with the scope, subject and time of observation, fully describes the state of the process - its effects and which provides objective information in the form of descriptive or numerical reporting parameters.

Key performance indicators (KPI) are quantified performance measures of the organization - its goals. The process of processes performance analysis, in general, consists of actions shown in Fig. 1.

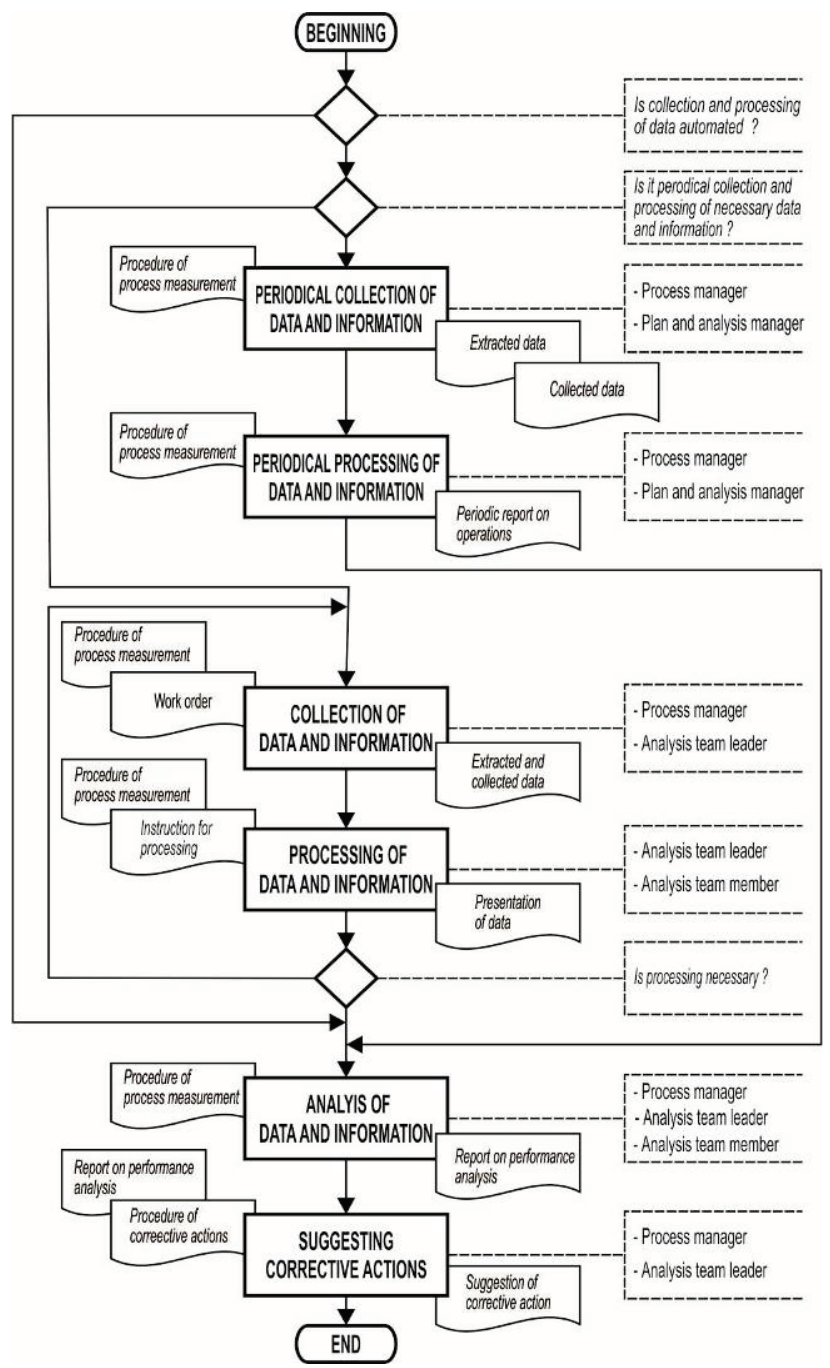

Figure 1 Process flow diagram of process performance analysis

Process flow diagram of process performance analysis, shown in Fig. 1, is described in detail in Djuric et al. 2013 [18].

\subsection{A Review of Business Requirements}

The subject of case study in this paper is a large company with over 1.000 employees, whose core business is the exploitation of mineral resources (bauxite, silica sand, zeolite and others). Besides the core business, the company is engaged in engineering, construction, transport of goods, passenger transport, wood processing, tourism, trade etc. The detailed structure of company processes is given in section 4.1 of this paper, in Fig. 5.

The company's goal is to improve its information system for more efficient and effective planning, organizing, implementation and control of business processes by developing a specific client application Portal for business processes performance management. 
Monitoring of the processes performance will be used as an incentive for continuous processes improvement. In this paper, supply and sales processes were selected for monitoring because these are the primary processes of company. System should generate the performance of business processes - defined key performance indicators (KPI) used by organization's management for measuring improvements in achieving startegic goals. KPI should correspond to the nature and size of the organization and its products/services, processes and activities.

One or more KPI can be defined for one process, in order to ensure information that is measurable, accurate, reliable and useful. They are used for the implementation of corrective actions when performance is not consistent with the objectives, or to improve the efficiency and effectiveness of the process. The following key performance indicators were defined, for selected processes of supply and sales in the company:

\section{The supply process:}

- $I Q S U$ - Index of quality of supply,

- IRO - Index of submission of requests for offer,

- $\quad I S O$ - Index of submission of supplier's offer,

- ISD - Index of supply delays;

\section{The sales process:}

- ISC - Index of success of contacts with customers,

- $\quad$ ISOB - Index of submission of offers to the buyer,

- IDD - Index of delays in delivery,

- IQSA - Index of quality of sales.

The system should provide an overview of the process KPIs in a defined period of time (month, quarter, year). Access to informations should be limited in accordance with the authorization of a system user. It is necessary to use data from an existing integrated information system (ERP). The system should be implemented as a SOA solution with the use of Silverlight technology. A web portal should be created for the interaction between user and system.

\section{THE ARCHITECTURE SOLUTION \\ 4.1 The Solution Basis}

Based on the business requirements, the scope of the system and its relationship with the environment is defined. Conceptual architecture given in Fig. 2 is a service-oriented vision of the system, at the highest level, which is the basis for construction of services for the process performances analysis and future applications.

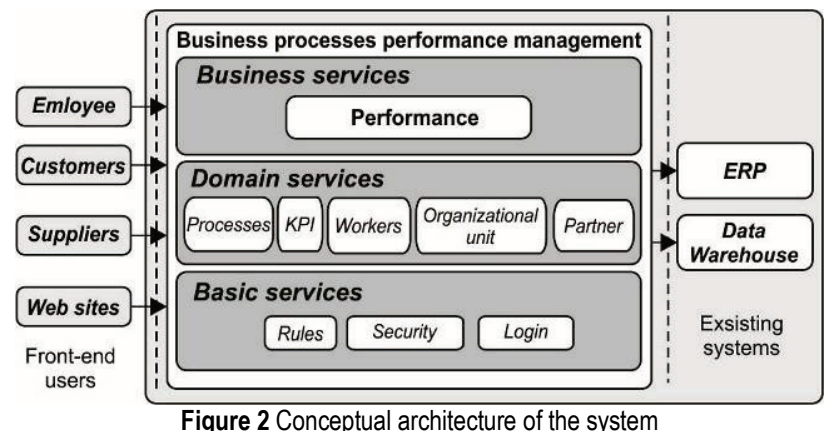

At the entrance of the system are potential users: employees, customers, suppliers, etc. In the central part is the initial set of services that should enable business processes performance management and which are divided into three groups: business services, domain services and basic services.
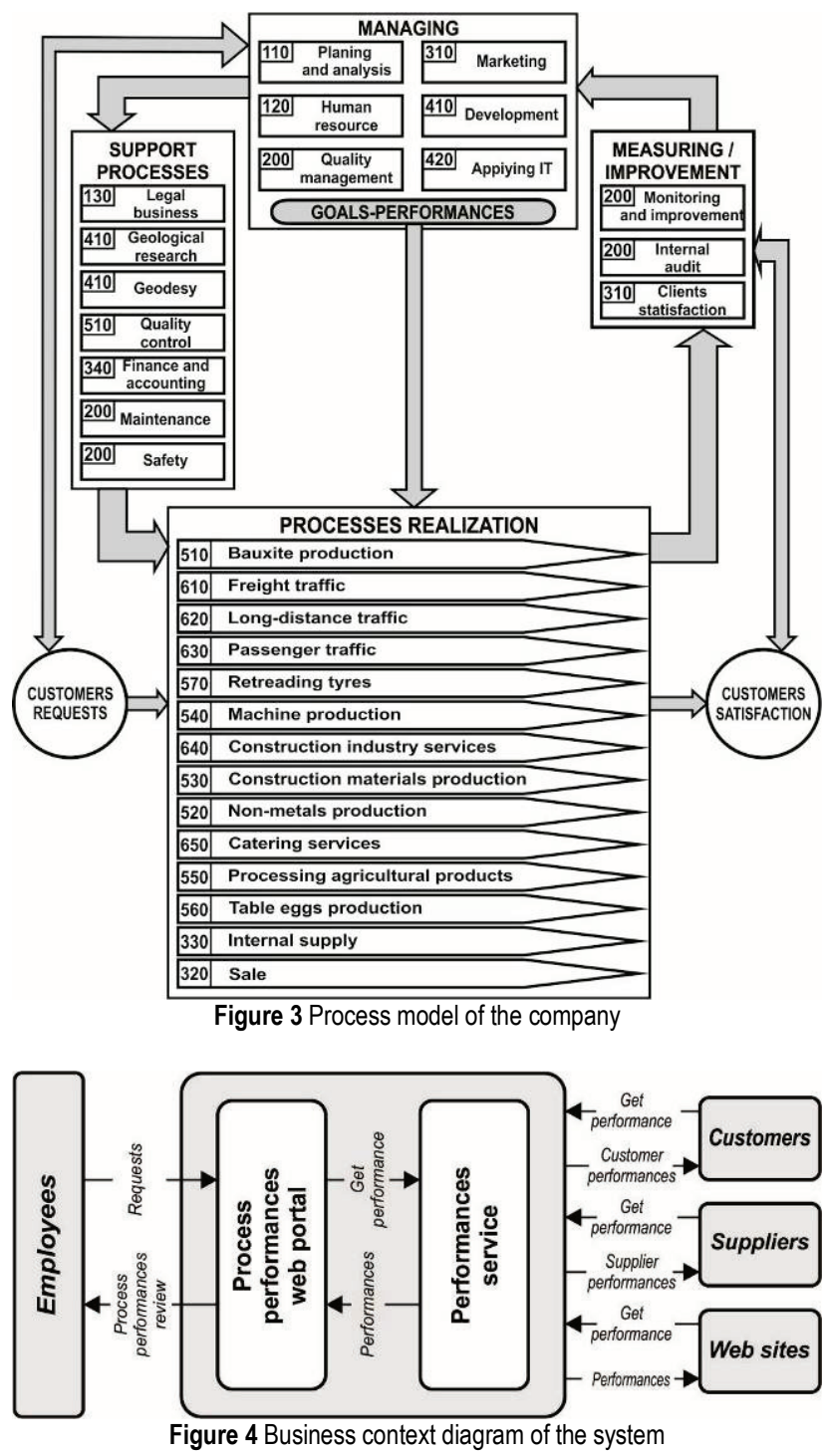

The first step in building business architecture is to define the value chain of the company, based on the company's process model (Fig. 3).

The second step in the business analysis is to build a conceptual architecture of the system that identifies the major participants in the company's value chain. Business context diagram of the system is shown in Fig. 4.

\subsection{The Architecture of the Software Solution}

One of the requirements is that the service Performance supports corporate $n$-tier Web portal. It is shown in Fig. 5 how the service Performance fits into the n-tier architecture.

The scope of the system for process performance management is determined by solid lines, and the boundaries between layers are represented by dashed lines. Presentation layer is implemented as Silverlight Web portal. 


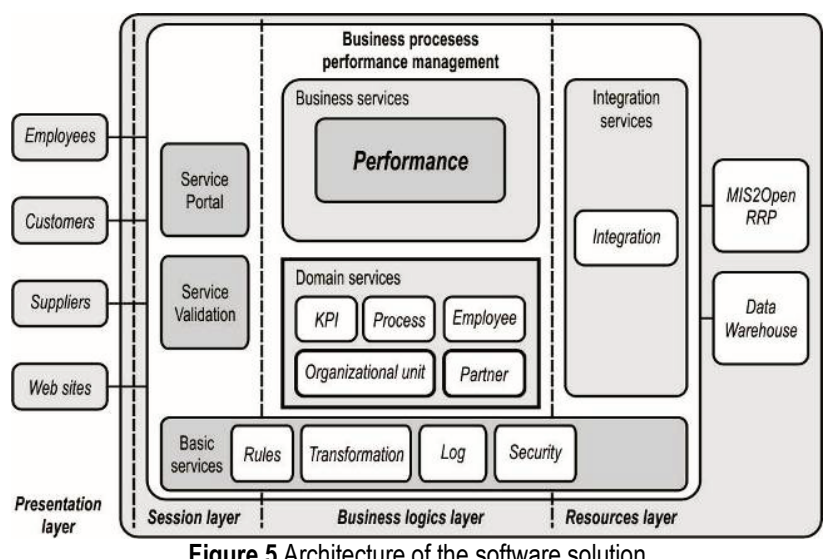

Figure 5 Architecture of the software solution

Software solution also defines the security aspects authentication, authorization, confidentiality and integrity.

User authentication is done at the Web portal via $W S$ Security SOAP messages. When interacting with the service, customers and suppliers confirm their identity, which is secured using SSL or VPN connection. This approach meets the current authentication requirements and takes care of future requirements.

Authorization is provided by using mechanisms of roles and rules. The basic rule is that employee who uses the system has the ability to view data related to the organizational unit to which he belongs, and to subordinate organizational units. Customers and suppliers, through the potential future use of the system, will have the ability to view data related exclusively to the business transaction in which they participated.

Confidentiality is ensured with a minimum impact on performance. The eventual use of the system by customers and suppliers is secured by the data encryption. For these purposes SSL and VPN connection provides "end-to-end" data confidentiality.

Integrity, as such an important security aspect, is secured by using the WS-Security SOAP messages, or SSL or VPN connections.

\subsection{Designing of DW (Data Warehousing)}

A methodology that includes the following steps is used in designing $D W$ (Data Warehousing) database:

\subsubsection{Identification of User Requirements}

The process of making $D W$ database is limited to, on the one hand, the needs and expectations of information user, and on the other hand, to the availability of data from operational database and other sources.

In order to identify the users' needs, interviews of the users were conducted in the company to find responses to the following questions:

- based on which indicators users make decisions,

- what level of detail of these indicators is needed and how they are calculated,

- to which time intervals these indicators are related,

- what affects the size of these indicators and

- which business factors largely affect these measures?

Based on the results of interviews the following general elements are established:
- list of Key Performance Indicators (KPIs) for all processes in company,

- method for calculating the size of each KPI, with the necessary inputs and places of their generation,

- frequency of KPIs analyses and reporting, which is set for weekly, monthly and yearly period,

- criteria, in the form of limiting values for KPIs, which generate the need to take improvement actions.

Details on the structure of KPIs are displayed in Djuric et al, 2010 [7], Djuric et al, 2013 [18].

\subsubsection{Logical Design}

Logical design of $D W$ database is conducted by Kimball/Ross mehtodology (The Data Warehouse Bus Archittecture - DWB) (Kimball and Ross, 2006 [12], Kimball and Caserta [13]) in the following steps:

- Determining the collection of related facts (Data Mart) and associated fact tables,

- Identification of the performance's dimensions,

- Preparation of the initial $D W B$ architecture,

- Designing facts relation schemes and dimensions of process performance,

- Integration and

- Performance adjustment on the logical level.

\subsubsection{Design of Data Mart and Corresponding Fact Table}

Data Mart is a collection of related facts that are used together. Each Data Mart contains at least one fact table. For each fact table, the level of detailness of data on business factors is determined and is reflected on the lowest unit of the time dimension.

Data Mart Performances are presented in Tab. 1 and include, in the respective phase, only one fact table.

Table 1 Data Mart Performances facts

\begin{tabular}{|c|c|c|}
\hline Data Mart & Table of facts & The level of data detailness \\
\hline Performances & $\begin{array}{c}\text { Key } \\
\text { performance } \\
\text { indicators }\end{array}$ & $\begin{array}{c}\text { The process performance by } \\
\text { months, organizational units and } \\
\text { employees }\end{array}$ \\
\hline
\end{tabular}

\subsubsection{Identification of Dimensions}

Based on the level of data detailness from the fact tables and identified user requirements, the identification was conducted to identify dimensions of process performance. For each business indicator (the fact), one dimension is defined.

The identified dimensions in the company are shown in Tab. 2.

Table 2 Data Mart Performances dimensions

\begin{tabular}{|c|c|c|}
\hline Data Mart & Table of facts & Granularity of data \\
\hline Performances & $\begin{array}{c}\text { Key } \\
\text { performance } \\
\text { indicators }\end{array}$ & $\begin{array}{c}\text { Year, quarter, month, sector, } \\
\text { organizational unit, employee, } \\
\text { process, KPI }\end{array}$ \\
\hline
\end{tabular}

\subsubsection{Designing Facts Relation Scheme}

Development of dimensional model for Data Mart Performances is divided into two parts. 
The first is designing fact relation schemes and the other is designing dimension relation schemes.

Designing of the facts features is conducted with the activities: identifying facts features, identifying the source (usually an operational database) and the definition of the algorithm for facts calculating.
For the Data Mart Performances the following measures shown in Tab. 3 are identified, including a description of semantics, data source and methods of calculation.

Table 3 Data Mart Performances calculation

\begin{tabular}{|c|c|c|c|}
\hline Fact feature & Description & Method of calculation & Source of data \\
\hline ser_num & Serial number & It automatically generates & - \\
\hline year & $\begin{array}{l}\text { Year for which analysis is } \\
\text { performed }\end{array}$ & Retrieves from the given parameters & Object of class Performance \\
\hline quarter & $\begin{array}{l}\text { Quarter for which the performance } \\
\text { analysis is performed }\end{array}$ & Retrieves from the given parameter & Object of class Performance \\
\hline month & $\begin{array}{l}\text { Month for which analysis is } \\
\text { performed }\end{array}$ & Retrieves from the given parameters & Object of class Performance \\
\hline sector & $\begin{array}{l}\text { Sector for which analysis is } \\
\text { performed }\end{array}$ & Retrieves from the operational database & Column code_org_unit from table org_unit \\
\hline code_org_unit & $\begin{array}{l}\text { Org. unit for which analysis is } \\
\text { performed }\end{array}$ & Retrieves from the operational database & Column code_org_unit from table org_unit \\
\hline id_num & Identification number of employee & Retrieves from the operational database & Column id_num from table employee \\
\hline code_pro & $\begin{array}{l}\text { Process for which the analysis is } \\
\text { performed }\end{array}$ & Retrieves from the operational database & Column code_pro from table process \\
\hline code_KPI & Key performance indicator & Retrieves from the operational database & Column code_KPI from table $K P I$ \\
\hline rating & KPI rating & $\begin{array}{l}\text { Calculates from the KPI's participation in } \\
\text { appropriate scope }\end{array}$ & Tables evid_supply, evid_sales, plan_cont and ERP \\
\hline data & Data on KPI & data $=\frac{\sum \text { data } * \text { num_records }}{\sum \text { num_records }}$ & Tables evid_supply, evid_sales, plan_cont and ERP \\
\hline num_records & $\begin{array}{l}\text { Number of records from which to } \\
\text { calculate KPI }\end{array}$ & $\begin{array}{l}\text { Summarizes the number of items for a } \\
\text { particular KPI }\end{array}$ & Tables evid_supply, evid_sales, plan_cont and ERP \\
\hline ser_num & Serial number & It automatically generates & - \\
\hline
\end{tabular}

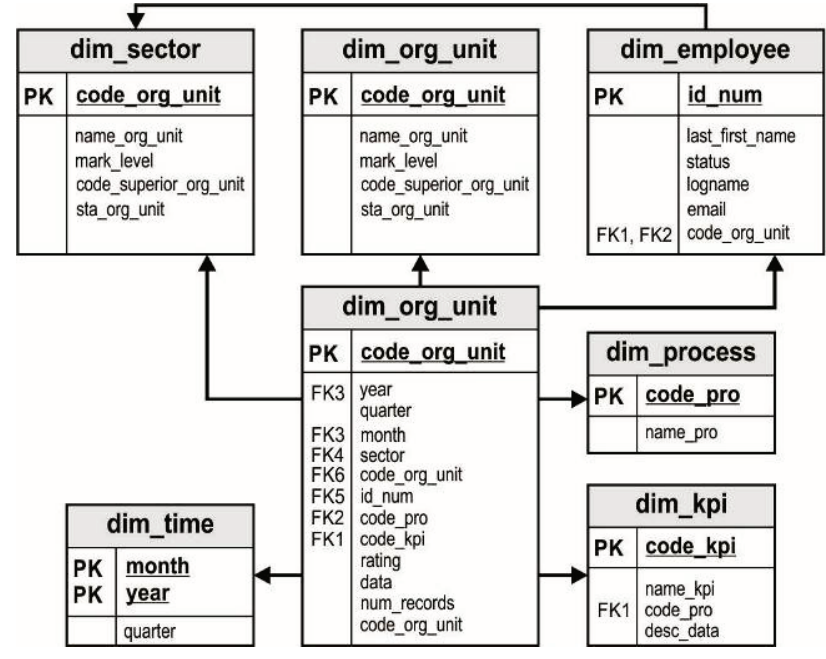

Figure 6 Fact table (Performance (fact_KPI))

\subsubsection{Designing Dimensions Relation Scheme}

In designing dimensions relation schemes the fact table (Fig. 6) is fully normalized, to store each unique combination of key of dimensions elements and with that combination calculates the corresponding values, without duplication.

Therefore, all facts are dependent only on the overall (foreign) key.

\subsection{Development of WCF (Windows Communication Foundation) Service}

Service storage, presented in Fig. 7, contains a broader set of identified services in comparison to the conceptual architecture. Service storage describes the main responsibilities of individual services, and it allows making decisions regarding the inclusion of new functions into the design and implementation of service in the future.

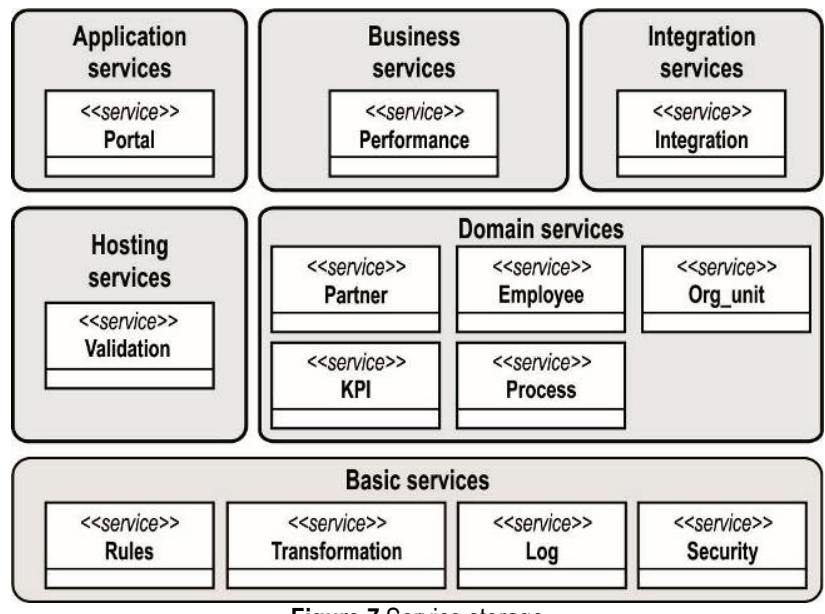

Figure 7 Service storage

The basic elements of WCF service from Fig. 7 are as follows:

- Portal - application service responsible for the separation of presentation, in this case the Web portal 
from the service Performance and determination of the individual preferences of users and implementation of the logic on the individual user level. In this way it leaves the possibility to use all implemented services in the future customization of the presentation for other purposes;

- Performance - business service of the highest level, responsible to provide the relevant information about the performance of business processes, in accordance with defined parameters, at the request of service users;

- Integration - integration services responsible for accessing to all company applications and data, so that they can be used by other services;

- Validation - utility service responsible for validation of entered data and user requirements;

- KPI, process, Org unit, employee, partner - the domain services which are responsible for providing relevant data corresponding to one or more domain entities;

- Rules, Transformation, Logging, Security - basic services responsible for: providing information about the current rules, transformation of data, controlling of user activity, and ensuring security.

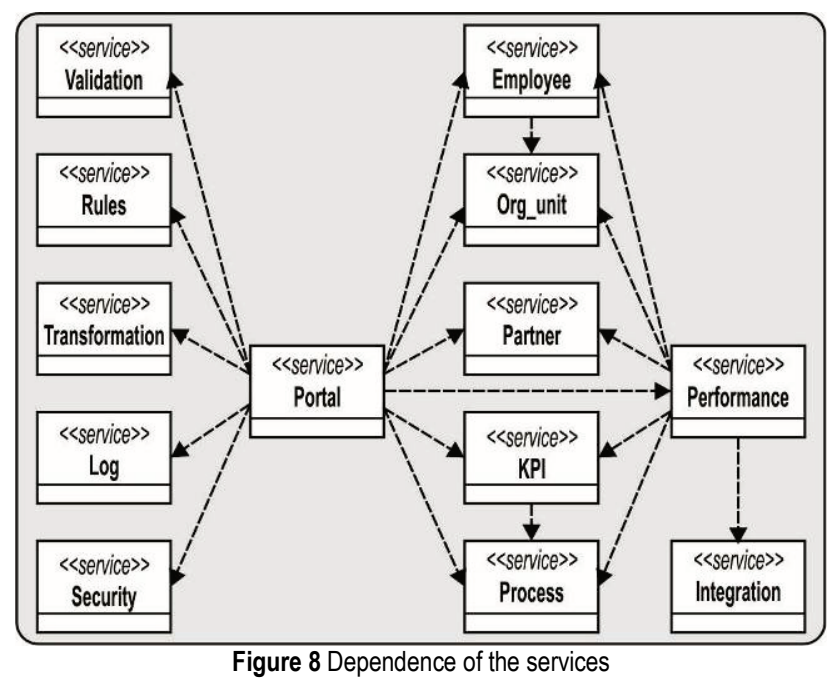

In service interface designing a great attention is paid to the degree of dependency between services. In regard to this, the simple service interaction is designed with minimal dependence, whereby certain groups of services, such as service entities and basic services, remained independent of other services, in order to have great potential for other uses (Fig. 8).

In the applied application $W C F$ service is designed by separation of the application code and configuration file, as a way of more flexible approach in which three steps were used: defining the service contract, defining the endpoint, and service hosting (in order to receive messages), Löwy, 2007 [14].

Without influencing the generality of solutions, service Performance is applied to measure the KPI of two processes - supply and sales.

The service is developed in Visual Studio 2010 SP1 developing environment as the . NET WCF service (Performance.svc) by using the $C \#$ language, with separation of the source code and configuration file (Web.config).

Detailed instructions for measuring KPIs of supply and sales processes, which are applied in the private methods individually for each defined KPI, given in Schmitz et al [15], Busi, 2005 [16] and Rodriguez et al [17].

Methods InputUpdateFactKPI and PrepareFactKPI perform automatic entry into the fact table fact_KPI for process performances that resulted from the operation GetPerformance.

Calling methods GetPerformanseFromFactKPI run queries that take adequate process performances from the fact table fact KPI which are loaded in the application Portal, giving a review of KPI in a defined time period, including the possibility of overview of KPI for individual organizational units, employee and partner who were involved in the implementation of business processes.

Integration service is the service responsible for the access to existing company data, operating base of ERP system and designed Data Warehouse base $D W$.

\subsection{Development of Silverlight Application PORTAL}

Silverlight Web portal was developed in Visual Studio 2010 SP1 environment, using C\# programming language for programming "code-behind" classes and Silverlight technologies. The Form-based authentication is applied by using the WAT (Web Site Administrative Tool) to create user accounts.

Users login to the portal is implemented using the Login control.

Reference and finding $W C F M E X$ service endpoint is solved by using the Add Service Reference (ASR) tool from the developing environment Visual Studio 2010 SP1.

Finally, Silverlight Web portal allows users different views of graphs and tables with KPI ratings of supply and sales processes. By calling Submit the service Performance is called, which calculates and returns the process performance data to Web portal, in accordance with defined parameters, and results are presented in tables and graphs. Both displays are updated by selecting Data or Ratings. Review of informations is limited with the personalization of content, in accordance with positions and authorizations of system users.

Four reviews of the obtained processes performance are possible: review of KPI during the specified time period and by months, review of processes ratings during the specified time period and in parallel by months, including the possibility of obtaining these views for individual organizational units, employee or a partner, who were involved in implementation of business processes. Also, it is possible to view KPI's of only one process or the review of only one particular KPI of process.

Key performance indicators of supply and sales processes in observed company are shown in Figs. $9 \div 14$. 
Portal - Processes for period Start Record Performances Report Indicator
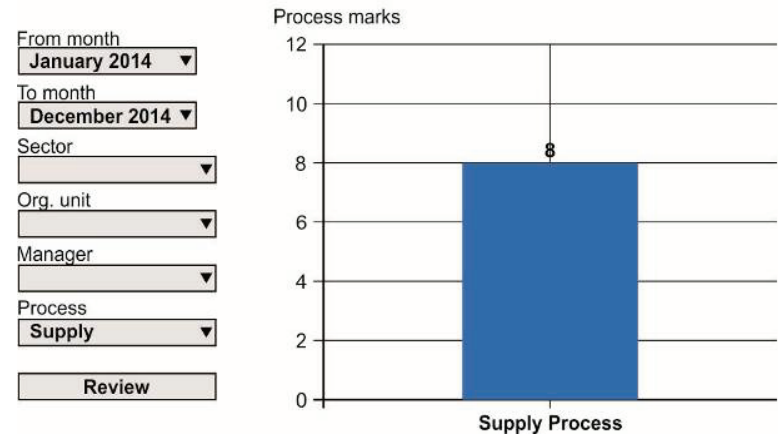

Figure 9 Valuation of the supply process for the year 2014

Portal - Processes for period Start Record Performances Report Indicator
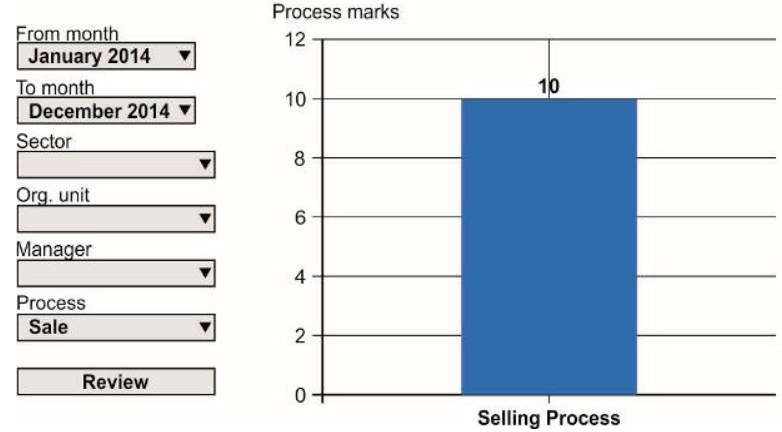

Figure 10 Valuation of the selling process for the year 2014

Portal - KPIs for period Start Record Performances Report Indicator
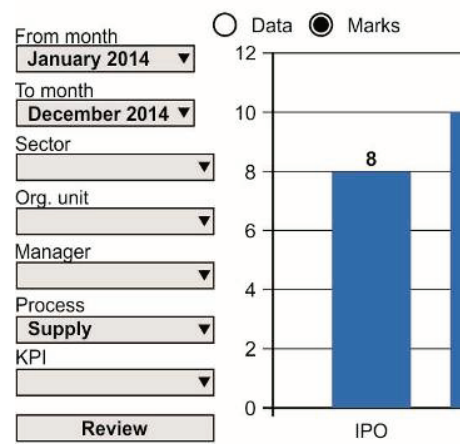

Figure 11 Data of KPI's supply process for the year 2014

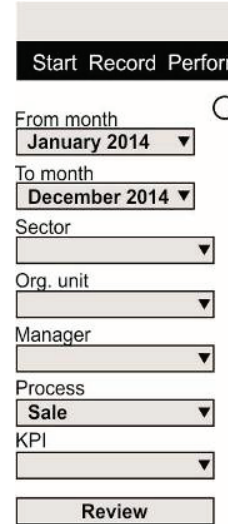

Portal - KPIs for period Performances Report Indicator
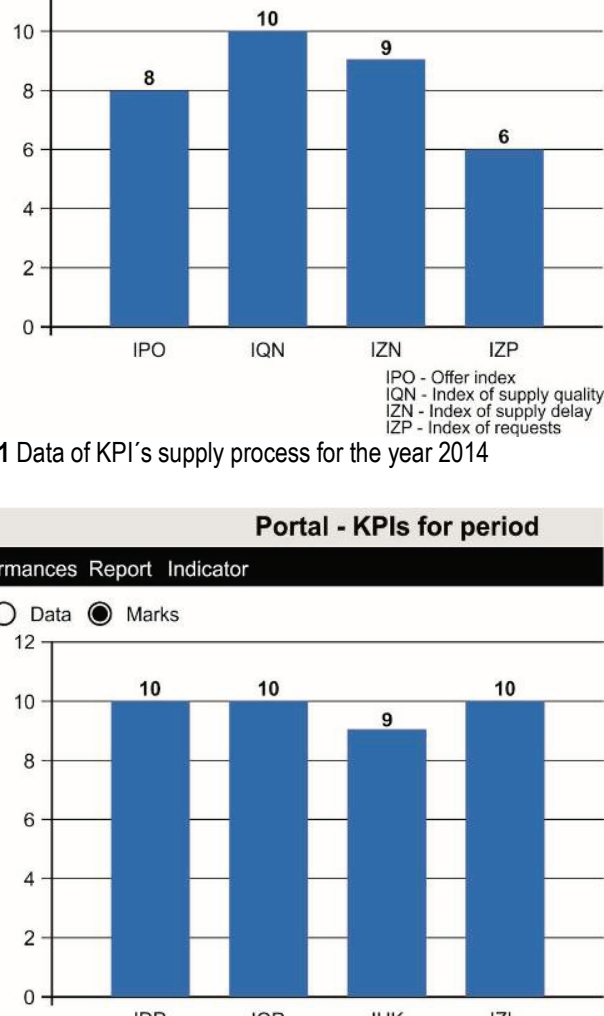

Figure 12 Data of KPI's selling process for the year 2014

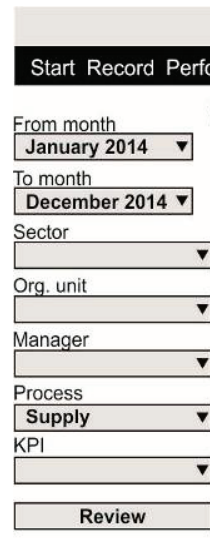

Portal - KPIs by months Start Record Performances Report Indicator

$\bigcirc$ Data $\bigcirc$ Marks

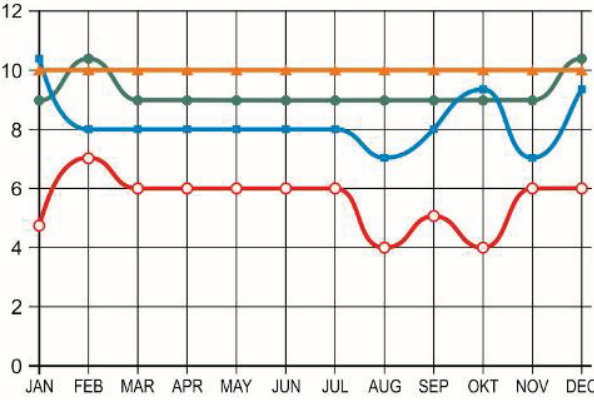

$=$ IPO - Offer index

IQN - Index of supply quality

$\because \quad$ IZN - Index of supply delay

Figure 13 Valuation of the supply process for period January - December 2014

Portal - KPls by months

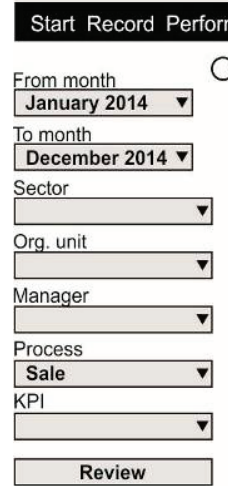

port Indicato
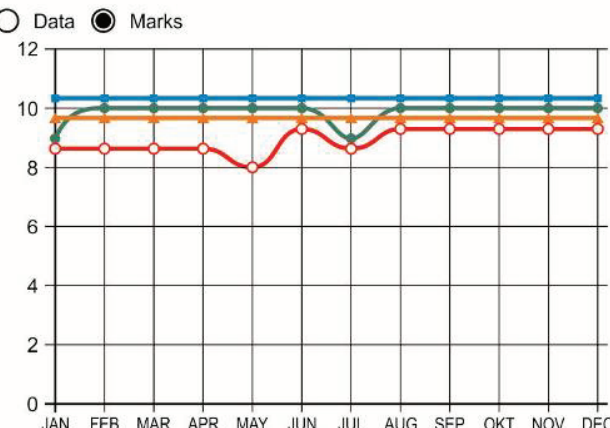

- IDP-Requests index

- IQP - Index of sale quality

$-\infty$ IUK - Index of sales contacis

Figure 14 Valuation of the selling process for period January - December 2014

\section{CONCLUSION}

Automation of process performance management allows efficient process performance analysis in the company. Automating the collection and processing of necessary data and information in the company provides more accurate, more complete and more up to date information necessary for keeping records on the business processes, especially if these records are governed by appropriate procedures. Thus, performance measurement process focuses on a certain period of time and performs more effectively, it enables analyzing the results and efficient way to resolve inconsistencies with the goals of process improvement.

The analysis of process performance, i.e. key performance indicators (KPI) as described above, may allow timely determination whether the processes are implemented according to specified requirements and objectives of the company as well as processes capability to achieve planned results.

Performance measurement based on KPI is the basis for successful management of business systems. Without the proper metrics, such as KPI, it is not possible to properly assess the quality of processes and make decisions for business processes reengineering in order to improve their effectiveness and efficiency. 
Applied solutions presented in this paper directly link IT resources with business goals of the organization, helping the organization to build connections with customers and suppliers, and internal links of organizational units, allowing more accurate and more complete business information, crucial for making quality decisions, and at the same time supporting key business processes through the increased availability of information which significantly influence increasing the total effectiveness of the company.

The case study presented in this paper is limited to the purchase and sales processes in the respective company, because the main goal of the paper was to demonstrate the way of functioning of the programming tools to automate performance management processes. In actual, practical cases, the processes of performance management are subject to all the processes of the company.

\section{REFERENCES}

[1] List, B., Bruckner, R. M., \& Kapaun, J. (2005). Holistic software process performance measurement: From the stakeholders' perspective. Proc. DEXA Workshops, 941947. https://doi.org/10.1109/DEXA.2005.109

[2] Kaplan, R. S. \& Norton, D. P. P. (1999). The Balanced Scorecard - Measures that drive performance. Harvard Business Review - HBR January-February 1992, 71-80.

[3] Kaplan, R. \& Norton, D. (2001). Commentary transforming the balanced scorecard from performance measurement to strategic management: part and, accounting horizons. American Accounting Association, 15(1), 87-104.

[4] Wang, Q., Jiang, N., Gou, L., Liu, X., Li, M., \& Wang, Y. (2006). BSR: a statistic-based approach for establishing and refining software process performance baseline. ICSE'06: Proceeding of the $28^{\text {th }}$ international conference on Software engineering, New York: ACM Press, 585-594. https://doi.org/10.1145/1134285.1134368

[5] Abran, A. et al. (2004). Guide to the software engineering body of knowledge (swebok), IEEE Computer Society, Aug. 2004.

[6] Kaplan, R. \& Norton, D. (2001). The Strategy-Focused Organization: How Balanced Scorecard Companies Thrive in the New Business Environment, Harvard Business School Press, Boston, Massachusetts.

[7] Đuric, Z., Maksimovic, R., \& Adamović, Z. (2010). Key performance indicators in a Join-Stock Company. Afr. J. of Bus. Manage, 4(6), 890-902.

[8] Garengo, P. (2009). A performance measurement system for SMEs taking part in Quality Award Programmes. Total Qual. Manage. Bus. Excel. 20(1), 91-105. https://doi.org/10.1080/14783360802614307

[9] Skibniewski, M. J. \& Ghosh, S. (2009). Determination of Key Performance Indicators with Enterprise Resource Planning Systems in Engineering Construction Firms. J. Constr. Eng. Manage. 135(10), 965-978. https://doi.org/10.1061/(ASCE)0733-9364(2009)135:10(965)

[10] Gongbo, L., Geoffrey, Q. S., Ming, S., \& John, K. (2011). Identification of Key Performance Indicators for Measuring the Performance of Value Management Studies in Construction. J. Constr. Eng. Manage. 137(9), 698-707. https://doi.org/10.1061/(ASCE)C0.1943-7862.0000348

[11] Radujković, M., Vukomanović, M., \& Dunović-Burcar, I. (2010). Application of key performance indicators in South-Eastern European construction. J. Civ. Eng. Manag. 16(4), 521-530. https://doi.org/10.3846/jcem.2010.58

[12] Kimball, R. \& Ross, M. (2006). The Data Warehousing Toolkit, Published by Wiley Publishing, Inc.
[13] Kimball, R. \& Caserta, J. (2006). The Data Warehousing ETL Toolkit, Published by Wiley Publishing, Inc.

[14] Löwy, J. (2007). Programming WCF Services, O'Reilly Media, Inc.

[15] Schmitz, J. \& Platts, K. W. (2004). Supplier logistics performance measurement: indications from a study in the automotive industry. International Journal of Production Economics, 89, 231-243. https://doi.org/10.1016/S0925-5273(02)00469-3

[16] Busi, M. (2005). A management Framework for Performance management of Integrated Logistics Operations. Annual Conference of POMS, Chicago, April 29 - May 2, 2005.

[17] Rodriguez, R., Alfaro, J. J., \& Ortiz, A. (2009). Quantitative relationships between key performance indicators for supporting decision-making processes. Computers in Industry, 60(2), 104-113. https://doi.org/10.1016/j.compind.2008.09.002

[18] Djuric, Z. \& Maksimovic, R. (2013). Measuring and analysis of the key performance indicators in an industrial enterprise applying information system. XI Balkan Conference on Operational Research - BALCOR 2013, Belgrade \& Zlatibor, 7 - 11 September, 2013, 69-78.

[19] International Organization for Standardization, ISO 9001:2015 - Quality management systems - Requirements, (2015).

Contact information:

Nemanja TASIĆ, Ph.D. Assistant Professor

University of Novi Sad, Faculty of Technical Sciences

Trg Dositeja Obradovića 6, 21000 Novi Sad, Serbia

E-mail: nemanja.tasic@uns.ac.rs

Željko ĐURIĆ, Ph.D.

Bauxite Corporation Milici

Lukić Polje bb, 75446 Milići, Bosnia and Herzegovina

E-mail: zeljko@ad-boksit.com

Dane MALEŠEVIĆ, Ph.D.

Kralja Tvrtka I 25, 78400 Gradiška, Bosnia and Herzegovina

E-mail:dmalesevic@blic.net

Rado MAKSIMOVIĆ, Ph.D.

University of Novi Sad, Faculty of Technical Sciences

Trg Dositeja Obradovića 6, 21000 Novi Sad, Serbia

E-mail: rado@uns.ac.rs

Nikola RADAKOVIĆ, Ph.D.

University of Novi Sad, Faculty of Technical Sciences Trg Dositeja Obradovića 6, 21000 Novi Sad, Serbia

E-mail: nikolar@uns.ac.rs 